\title{
The equatorial ionospheric response over Tirunelveli to the 15 January 2010 annular solar eclipse: observations
}

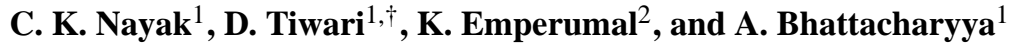 \\ ${ }^{1}$ Indian Institute of Geomagnetism, New Panvel (W), Navi Mumbai-410218, India \\ ${ }^{2}$ Equatorial Geophysical Research Laboratory (EGRL), Tirunelveli, India \\ $\dagger$ deceased
}

Correspondence to: C. K. Nayak (physics642@gmail.com)

Received: 4 July 2011 - Revised: 9 April 2012 - Accepted: 4 September 2012 - Published: 25 September 2012

\begin{abstract}
In this paper we present a case study of the annular solar eclipse effects on the ionization of $\mathrm{E}$ and $\mathrm{F}$ regions of equatorial ionosphere over Tirunelveli $\left[77.8^{\circ} \mathrm{E}, 8.7^{\circ} \mathrm{N}\right.$, dip $\left.0.4^{\circ} \mathrm{N}\right]$ by means of digital ionosonde on 15 January 2010 . The maximum obscuration of the eclipse at this station was $84 \%$ and it occurred in the afternoon. The E and F1 layers of the ionosphere showed very clear decrease in their electron concentrations, whereas the F2 layer did not show appreciable changes. A reduction of $30 \%$ was observed in the $f o \mathrm{~F} 1$ during the maximum phase of the eclipse. During the beginning phase of the eclipse, an enhancement of $0.97 \mathrm{MHz}$ was observed in the $f o \mathrm{~F} 2$ as compared to that of the control days. But the $f o \mathrm{~F} 2$ decreased gradually as the eclipse progressed and a decrease of $0.59 \mathrm{MHz}$ was observed towards the end phase of the eclipse. Observed variations in the $h^{\prime} \mathrm{F} 2$ and $h m \mathrm{~F} 2$ showed lower values than the control days, although $h m \mathrm{~F} 2$ was found to increase a bit during the eclipse. Observed variability in the E, F1 and F2 layer ionospheric parameters on the eclipse day and their departure from the control days are discussed as the combined effect of annular eclipse and presence of counter equatorial electrojet (CEEJ).
\end{abstract}

Keywords. Ionosphere (Electric fields and currents; Equatorial ionosphere; Ionospheric irregularities)

\section{Introduction}

A solar eclipse provides an excellent opportunity to explore the upper and lower ionospheric effects associated with an accurately estimated variation of solar radiation during the eclipse period. Study of the ionospheric response to a solar eclipse has been in place for decades, and extensive studies have been made with various experimental techniques, such as ionosondes, incoherent scatter radar, rockets, Faraday rotation measurements, global positioning system and satellite measurements (Evans, 1965a, b; Klobuchar and Whitney, 1965; Rishbeth, 1968; Hunter et al., 1974; Oliver and Bowhill, 1974; Cohen, 1984; Salah et al., 1986; Cheng et al., 1992; Farges et al., 2001; Tomas et al., 2007) as well as theoretical modeling (Le at al., 2008a, and references therein). Both the measurements and simulations show that the eclipse effect is larger in the midday than in the morning and afternoon, and also the decrease in electron concentration is greater in the $\mathrm{F} 1$ region than in the E region (Le at al., 2008a). The eclipse effect in the F2 region is larger at high solar activity than at low solar activity. In a recent study, the signatures of a total solar eclipse on ionospheric E, F1 and F2 regions, during the forenoon hours, have been reported by Adeniyi et al. (2007), as observed over equatorial station Ilorin, Nigeria. In the present investigation, we find that the decrease in electron density occurs throughout the $\mathrm{E}$ and $\mathrm{F} 1$ layer heights at about the same time, while, in the F2 region, the electron density decrease began at lower heights and extended progressively towards the layer peak.

A total solar eclipse during sunset hours on $11 \mathrm{Au}-$ gust 1999 highlighted the eclipse-induced changes in the evening time equatorial $\mathrm{E}$ and $\mathrm{F}$ regions in terms of sudden intensification of a weak blanketing Es layer, significant increase in $h^{\prime} F$ immediately following the eclipse and distinctly different spatial and temporal structures in the spread F irregularities.

Ionospheric response at low altitudes (D, E and F1 regions) is governed mainly by photochemical processes so 


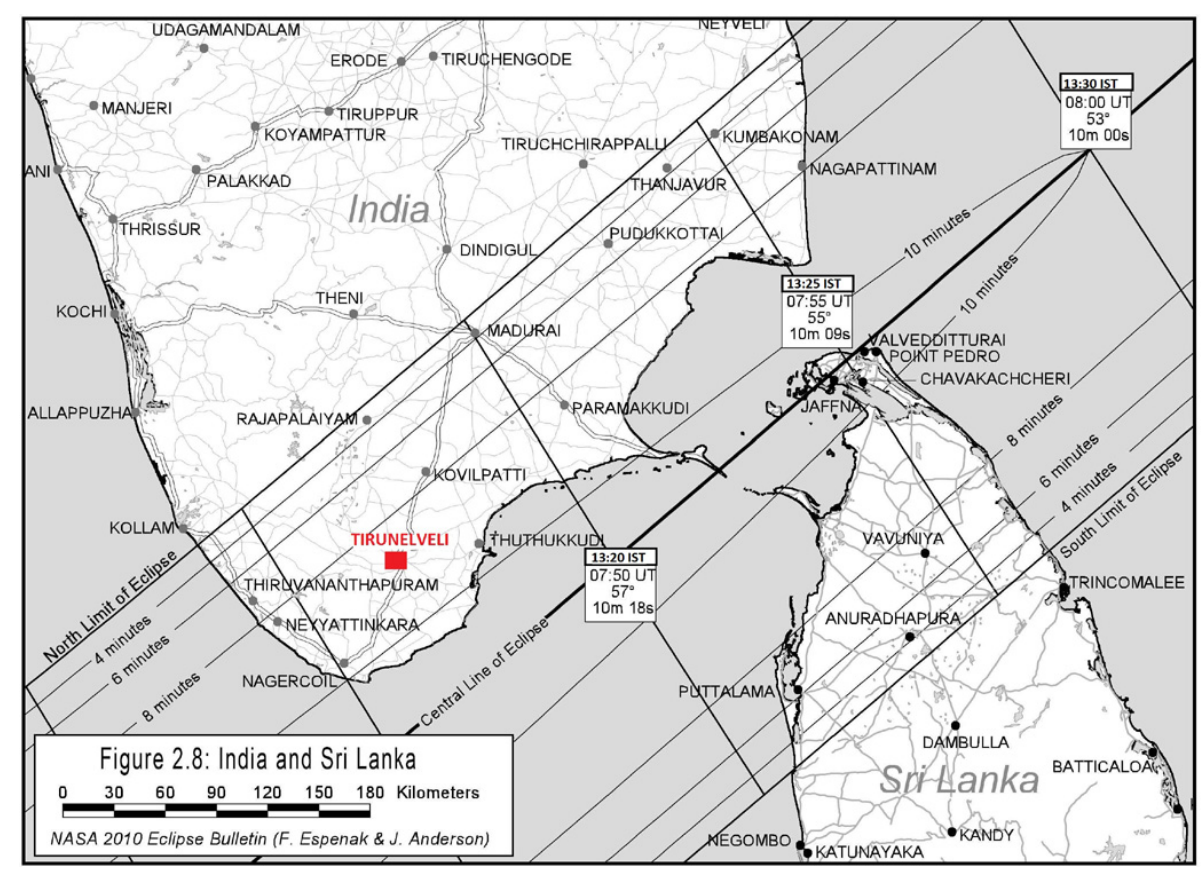

Fig. 1. Map describing the detailed path of the 15 January 2010 annular solar eclipse over India and Sri Lanka. The station Tirunelveli is shown on the map in filled red square.

that the decrease of solar radiation during an eclipse is expected to decrease the electron production rate and hence the electron concentration. However, the F2 layer behavior may be quite different as it is governed by photochemical processes as well as by electrodynamical and neutral forcing. When the $\mathrm{F}$ layer is normally in a state of quasi-equilibrium, the obscured changes in electron density during eclipse are almost entirely due to loss by recombination and production by photoionization (Skinner, 1967).

The annular solar eclipse of 15 January 2010 was particularly interesting in that it occurred near noon, thus avoiding the larger portion of normal diurnal variations, and it occurred on a magnetic quiet day of a solar minimum. The path of the annular eclipse that occurred on 15 January 2010 over Tirunelveli is shown in Fig. 1. The observational site Tirunelveli $\left[77.8^{\circ} \mathrm{E}, 8.7^{\circ} \mathrm{N}\right.$, dip $\left.0.4^{\circ} \mathrm{N}\right]$ has been marked on the map with a red square. The central part of the occurrence of maximum annularity is indicated by the thick black line. The time (in IST) of the occurrence of the eclipse annularity, the sun's altitude in degrees and its duration are marked on the map. At Tirunelveli, the details of the occurrence time in IST (UT $+5.5 \mathrm{~h}$ ) on the ground for this eclipse are as follows: the beginning of the eclipse at 11:07:57 IST, maximum magnitude of the eclipse at 13:16:51 IST and the end of eclipse at 15:06:52 IST. The maximum obscuration was $84.3 \%$ and eclipse magnitude was 0.918 at this station. The details of the eclipse are available at http://eclipse.gsfc.nasa.gov/SEmono/ ASE2010/ASE2010.html.
Table 1. Details of parameters during eclipse day and control days.

\begin{tabular}{lccc}
\hline Day & Ap & SSN & F10.7 \\
\hline 13 Jan 2010 & 7 & 21 & 90.5 \\
14 Jan 2010 & 4 & 18 & 89.9 \\
15 Jan 2010 & 4 & 18 & 85.3 \\
16 Jan 2010 & 1 & 16 & 84.2 \\
17 Jan 2010 & 1 & 12 & 82.6 \\
\hline
\end{tabular}

\section{Data analysis}

In order to assess the effect of solar eclipse on ionospheric parameters, an estimate must be made of the variations of these parameters in the absence of eclipse. In this study, high-resolution ionograms obtained at every 2 min using a Canadian Advanced Digital Ionosonde (CADI) operational at Tirunelveli have been used. Observations on the eclipse day (i.e. 15 January 2010) were compared with those of the two days each before and after the eclipse day chosen as the control days. All these days correspond to magnetic quiet days, and hence the observed changes are purely due to the solar eclipse. A list of control days and eclipse day along with corresponding values of Ap indices, sunspot numbers (SSNs), and F10.7 solar flux values is given in Table 1. The period of the eclipse falls within a low solar activity period where SSN varied from 12 to 21 . The control days and eclipse day ionograms were scaled manually at every $2 \mathrm{~min}$ during 09:00-17:00 IST to get the ionospheric parameters 
[a]

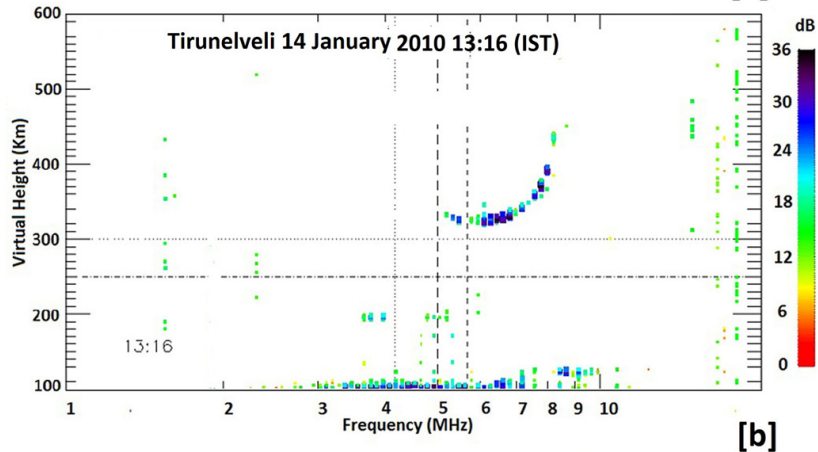

[b]

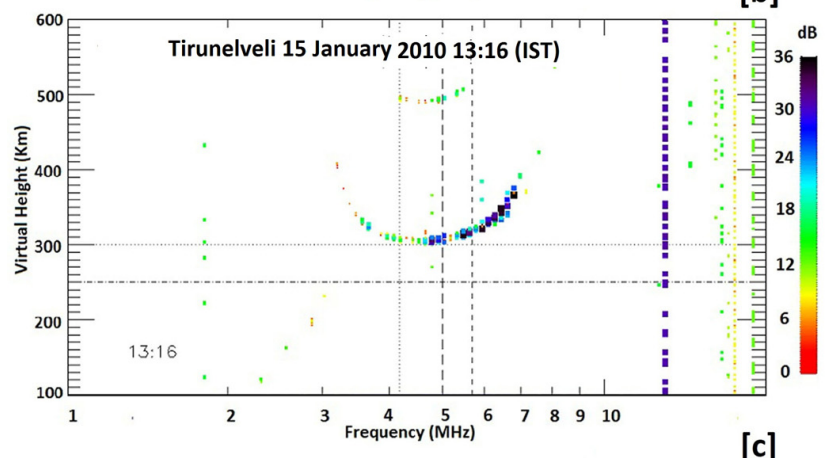

[c]

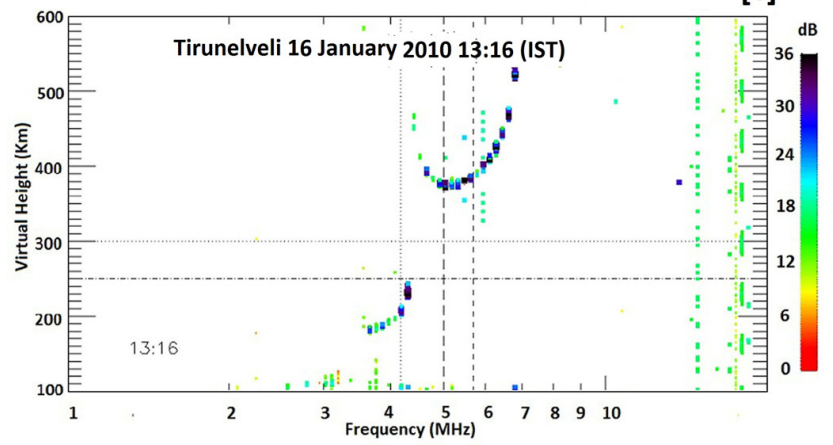

Fig. 2. Ionograms recorded at 13:16 IST (when the eclipse magnitude was maximum) on (a) 14 January, (b) 15 January and (c) 16 January 2010 .

(i.e. $f o \mathrm{~F} 1, h^{\prime} \mathrm{F} 1, f o \mathrm{~F} 2, h^{\prime} \mathrm{F} 2$ and $h m \mathrm{~F} 2$ ). For the control days, these parameters were further averaged for $30 \mathrm{~min}$ interval. The obtained data show a clear eclipse effect near the beginning, maximum and ending phase of the eclipse in the $\mathrm{E}$ and F1 regions. This study focuses on the investigation of eclipseinduced changes in the $\mathrm{E}, \mathrm{F} 1$ and $\mathrm{F} 2$ region of the ionosphere. In the $\mathrm{E}$ region, the changes in the electron density during eclipse are mainly due to production of electrons by photoionization and loss by recombination. However, significant changes in the electron density in the $F$ region may occur due to horizontal and vertical transport of ionization and temperature changes along with photochemical reactions. Analysis of photoionization and loss rate will be undertaken and communicated later.
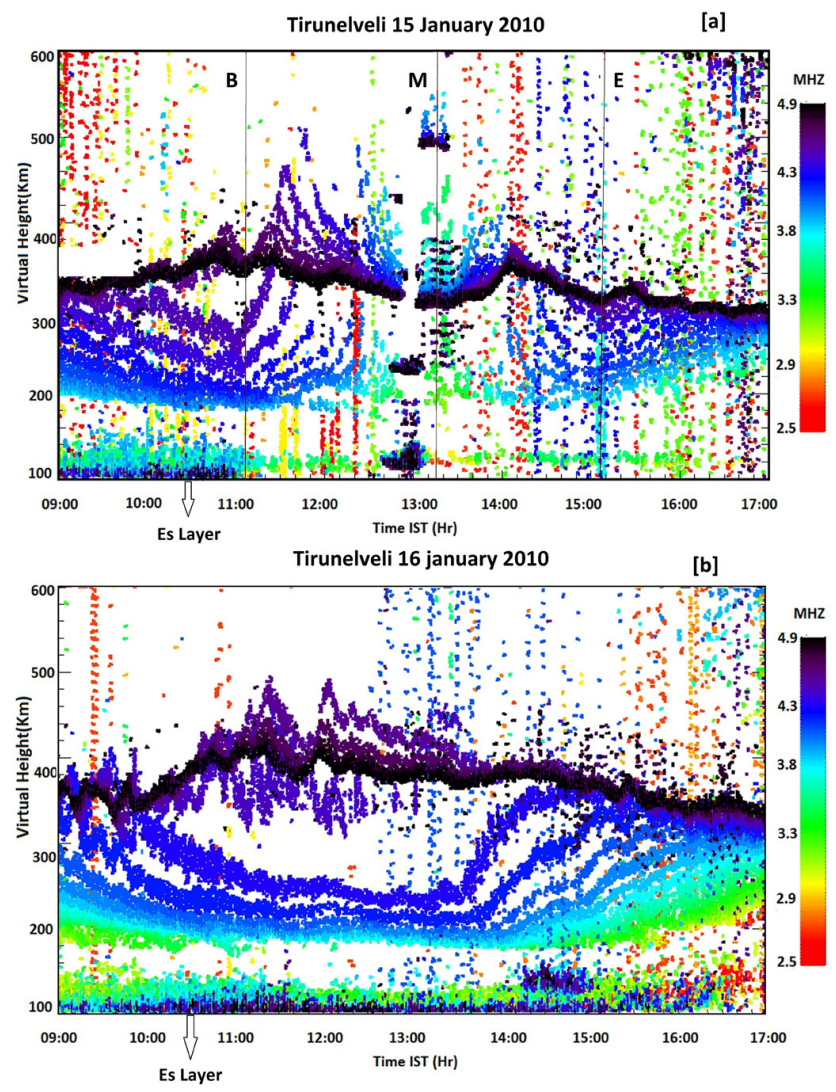

Fig. 3. Virtual height-time-frequency map observed by CADI at Tirunelveli on (a) 15 January and (b) 16 January 2010.

\section{Results and discussion}

For the purpose of comparison, Fig. 2a-c show the ionograms recorded on 14, 15 and 16 January 2010, at 13:16 IST, the time of maximum eclipse obscuration on the 15th. We can see clearly the absence of E and F1 layer traces and the presence of only $\mathrm{F} 2$ trace during the maximum phase of the solar eclipse during the eclipse day. Although the F1 layer critical frequency could be read from the CADI ionograms, the F1 and E layer traces could not be observed by the CADI as the electron density in these layers decreased to below the detection limit due to the solar ionizing radiation being cut down by the eclipse.

The results of the comparisons of the observed eclipse effects on ionospheric E, F1, F2 layers with those of control days are discussed in the following sections.

\subsection{E layer}

To demonstrate and compare strong solar eclipse effects on $\mathrm{E}$ and $\mathrm{F} 1$ regions of the ionosphere, virtual height-timefrequency maps obtained on 15 and 16 January 2011 are depicted in Fig. 3a and b, respectively. The vertical lines marked as B, M and $\mathrm{E}$ indicate the time of beginning, occurrence of maximum obscuration and the end of the eclipse. 


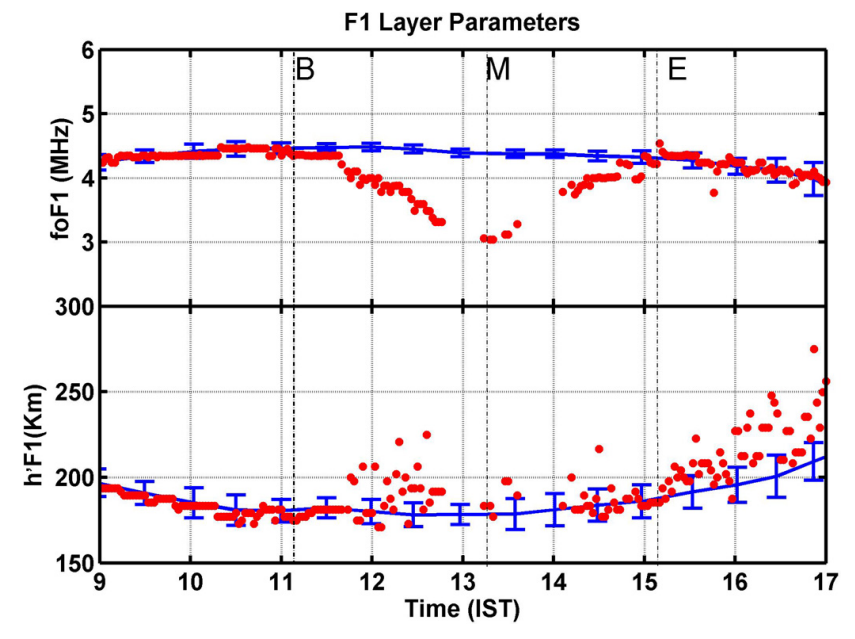

Fig. 4. Top and bottom panels show the temporal variations of the comparison of $f o \mathrm{~F} 1$ and $h^{\prime} \mathrm{F} 1$ from the control days. The blue line with error bar represents the mean values for the control days. Red stars correspond to the observations of eclipse day.

Normal Es and F1 layer were observed on the control day (i.e. 16 January 2011) during 09:00 to 17:00 IST. Distinctly different features on $\mathrm{E}$ and $\mathrm{F} 1$ layers of the ionosphere on the eclipse day in comparison with the control day have been noticed. The Es layer has been marked with an arrow. On 15 January 2010, a consistent change begins to be noticed in the Es layer from the onset time (11:07 IST) of eclipse. Es layer became thinner, weaker and disappeared around 11:14 IST and further continued to be weaker till the end of the solar eclipse and continued further till 17:00 IST. Weak blanketing Es was observed 12:44 IST onwards which further intensified around 13:00 IST with maximum fEsb (blanketing frequency of Esb layer) around $\sim 7 \mathrm{MHz}$. This Es ended at 13:04 IST. Sridharan et al. (2002) have also shown the occurrence of blanketing Es during the sunset hours of total solar eclipse on 11 August 1999 and suggested that this could be directly triggered by eclipse phenomena. On ionograms very weak traces of $\mathrm{E}$ layer were present, and hence $f o$ E could not be scaled, indicating the qualitative decrease of $f o$ Es and electron concentration.

\subsection{F1 layer}

Top and bottom panels of Fig. 4 show the comparison of observed temporal variation of $f o \mathrm{~F} 1$ and $h^{\prime} \mathrm{F} 1$, respectively, on the eclipse day with that on the control days. The blue line with error bar represents the mean values of the control days. Red stars represent the eclipse day observations. It is found that the foF1 does not show much day-to-day variability on the control days, as indicated by their small error bars. The eclipse began around the time period when the range of variation in the $f o \mathrm{~F} 1$ is usually very low, a period of quasiequilibrium state on normal day. The reduction of solar radiation intensity due to the eclipse upset this quasi-equilibrium between production by photoionization and loss of ionization due to recombination. Variation in $f o \mathrm{~F} 1$ shows inverse correlation with the maximum obscuration of the sun during the eclipse confirming that the solar radiation is the major controller of this variation. On the eclipse day, the critical frequency of $\mathrm{F} 1$ layer $(f o \mathrm{~F} 1)$ started decreasing gradually as the eclipse progressed. Not many changes were noticed in the beginning phase of the eclipse until 11:38 IST, but later on it reduced significantly by approximately $30 \%$ (51\% in electron density) around the maximum phase of eclipse from the control days. In the F1 region, electron densities are controlled by the balance between photoionization and chemical recombination. The formation of the F1 layer is mainly due to the altitude variation of the chemical loss (i.e. the transition between $\alpha N^{2}$ (quadratic) and $\beta N$ (linear) loss processes). In the F1 region, the square law loss $\alpha N^{2}$ and linear loss $\beta N$ are equally important. Lifetime of the electrons in the F1 layer is $\sim 1000 \mathrm{~s}$ around $200 \mathrm{~km}$ (Banks and Kockarts, 1973). Solar eclipse is a slowly varying process and it took almost four hours to cover the whole eclipse process from eclipse begin to end. The results of Skinner (1967) were for a period of high solar activity when the F1 region is not very distinct from the $\mathrm{F} 2$, and $68 \%$ reduction was noticed in the electron density of the F1 region. Adeniyi et al. (2007) have also shown that maximum decrease in the peak electron density as deduced from the critical frequency for F1 was $68 \%$ for the total solar eclipse of 29 March 2006 during low solar activity period. In Fig. 4, the foF1 started decreasing around 11:38 IST and a full recovery occurred at about 15:16 IST. The observed duration of decrease of this layer was $3 \mathrm{~h} 38 \mathrm{~min}$ and the eclipse duration was about $3 \mathrm{~h} 59 \mathrm{~min}$.

Observation of consecutive ionograms showed the $\mathrm{E}$ and F1 layers fade out during 12:46-13:14 IST and 13:3614:06 IST, and resulted as gap in the $f o \mathrm{~F} 1$. The $f o \mathrm{~F} 1$ shows large departure from the normal diurnal variations, ensuring that observed variations were eclipse-induced and are almost entirely due to loss by recombination and production by photoionization. With increase of eclipse obscuration, the production decreases and the loss rate at these heights is in a transition between $\alpha N^{2}$ (quadratic) and $\beta N$ (linear) loss processes, where $\alpha$ and $\beta$ are the recombination coefficient and $N$ is the electron density (Rishbeth and Garriott, 1969). The observed electron density was minimum around the maximum phase of the eclipse. After this it again increased gradually as the eclipse magnitude decreased.

The temporal variation of $h^{\prime} \mathrm{F} 1$ on the eclipse day shows some peculiar features. It seems that $h^{\prime} \mathrm{F} 1$ increases at some points of time during the eclipse. But it may not be a true height increase as the recombination is very dominant at this layer, and, due to diminished production, it appears that $h^{\prime} \mathrm{F} 1$ is going up. Oliver and Bowhill (1974) have shown that thermospheric temperature and $\mathrm{F} 1$ region ion composition show a large eclipse effect near the beginning and ending phase of eclipse. The so-called $F 1 \frac{1}{2}$, which was reported by Skinner 


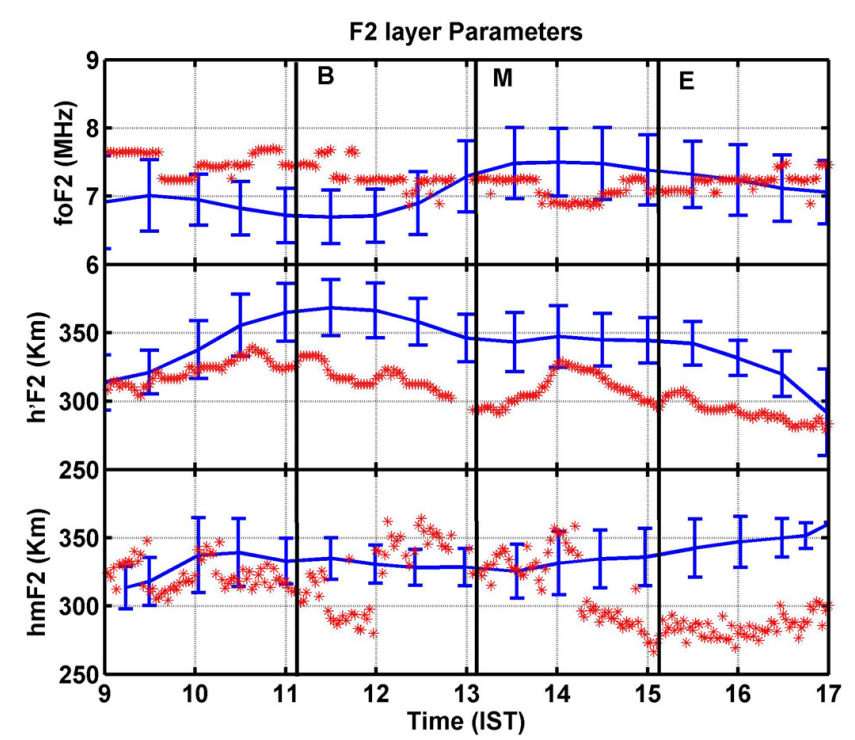

Fig. 5. Top, middle and bottom panels show temporal variations of the comparison of $f o \mathrm{~F} 2, h^{\prime} \mathrm{F} 2$ and $h m \mathrm{~F} 2$ from the control days. The blue lines with error bar represent the mean values for the control days. Red stars correspond to the observations of eclipse day.

(1967) as a prominent feature of the $\mathrm{F}$ region behavior during equatorial eclipses, was not observed during this eclipse.

\subsection{F2 layer}

The top, middle and bottom panels of Fig. 5 show temporal variation of $f o \mathrm{~F} 2, h^{\prime} \mathrm{F} 2$ and $h m \mathrm{~F} 2$. The blue lines with error bar represent the mean values of the control days. Red stars represent the eclipse day observations. The observed effect of the eclipse on the F2 layer as compared to E and F1 layers is quite different. The maximum observed decrease in $f o \mathrm{~F} 2$ was $\sim 0.59 \mathrm{MHz}$ around 14:00 IST. In fact, the observed values of the $f o \mathrm{~F} 2$ on the eclipse day are quite similar to those of the control days. From the observations, it is very clear that the values of the $f o \mathrm{~F} 2$ were higher compared to the control days before the onset of the eclipse and the maximum difference was $0.97 \mathrm{MHz}$. For the control days, it is found that the foF2 increases after 12:00 IST. But, for the eclipse day, no such rise in $f o \mathrm{~F} 2$ is observed. The $f o \mathrm{~F} 2$ starts to decrease around $13: 48$ IST, and the maximum decrease of $\sim 0.59 \mathrm{MHZ}$ is observed just after 14:00 IST. But, if we consider the $f o \mathrm{~F} 2$ before the onset of the eclipse, the actual decrease in $f o \mathrm{~F} 2$ may be higher than the value observed. The differences in $f o \mathrm{~F} 2$ from the control days before the onset of the eclipse were higher, and, following the control days' trend, it would have been even higher in the absence of the eclipse. However, observed values of the $f o \mathrm{~F} 2$ are found to be lower than the control days during the maximum to end phase of the eclipse. The possible reason may be that, during the presence of the eclipse, the ionization production is reduced and the transport processes in the $\mathrm{F}$ layer are affected due to the presence of the westward electric field which may in turn lead to the decrease in $f o \mathrm{~F} 2$. The time lag of the maximum decrease of $f o \mathrm{~F} 2$ with respect to the maximum eclipse obscuration is approximately $1 \mathrm{~h}$. Also, the observed effect of the eclipse on the F2 layer lasted for approximately $4 \mathrm{~h}$ from 12:00 IST to 16:00 IST as shown in Fig. 5. Stations away from the dip equator show the smaller decrease in $f o \mathrm{~F} 2$ (Le et al., 2008a). It should be noted that many previous studies with various measurements (e.g. Datta et al., 1959; Walker et al., 1991; Cheng et al., 1992; Boitman et al., 1999; Huang et al., 1999; Korenkov et al., 2003; Afraimovich et al., 2002; Baran et al., 2003) show that most of the $N m \mathrm{~F} 2$ (peak electron concentration in the F2 layer) decreases during solar eclipses, whereas the amplitude of $f o \mathrm{~F} 2$ decrease varies greatly from $0.2 \mathrm{MHz}$ to $1.6 \mathrm{MHz}$. Such a great difference may be induced by background differences in neutral gas and geophysical conditions (such as solar activity and geomagnetic activity level), and by differences in location and local time. In addition, it is possibly due to the measurement methods used with different spatial and temporal resolutions.

Higgs (1942) and Pierce (1948) reported that, during the total solar eclipse of 1 October 1940, there was an increase in $f o \mathrm{~F} 2$ followed by a decrease. Evans (1965b) also found a similar feature of $f \circ \mathrm{F} 2$ for the 20 July 1963 total eclipse. Evans proposed two necessary (but possibly not sufficient) conditions for an increase in the $f o \mathrm{~F} 2$ during a solar eclipse: first, the eclipse should be total or very nearly so (>90\%) at F1 region heights; secondly, the magnetic dip should be large $(I>60)$.

Excellent modeling efforts have been made to quantify local time and solar zenith angle, solar cycle, dip angle, and background $h m \mathrm{~F} 2$ effects on mid and low latitude ionosphere based on observations made during 7 solar eclipses events from 1970 to 2005 (Le et al., 2008a). Most of the observed differences in behavior of $N m \mathrm{~F} 2$ during eclipses can be attributed to differences in $\mathrm{O}^{+}$loss rate brought about by the background differences in the neutral molecular densities. The F2 region behavior during different eclipse events may be quite different accompanied with various amplitudes of decrease or even a small increase in the electron concentration.

Temporal variation of $h^{\prime} \mathrm{F} 2$ and $h m \mathrm{~F} 2$ on eclipse day shows departure from the control days observations. The $h^{\prime} \mathrm{F} 2$

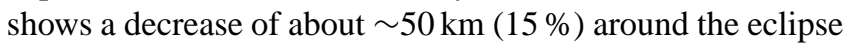
maxima. But an enhancement in $h m \mathrm{~F} 2$ was observed on the eclipse day. Skinner (1967) and Adeniyi et al. (2007) have shown $50-70 \%$ variation in $h m \mathrm{~F} 2$ during solar eclipse. From modeling studies, considerable amount of enhancement in the $h m \mathrm{~F} 2$ is expected on the eclipse day as compared to the control days (Le et al., 2009). But the observed $h m \mathrm{~F} 2$ does not show much enhancement. The $h m \mathrm{~F} 2$ increases considerably after 12:00 IST and is found to fluctuate till 14:00 IST, and later on it decreased gradually. Although the values of $f o \mathrm{~F} 2$ were higher than those of control days, still the enhancement was not as high as expected from simulations. As can be 


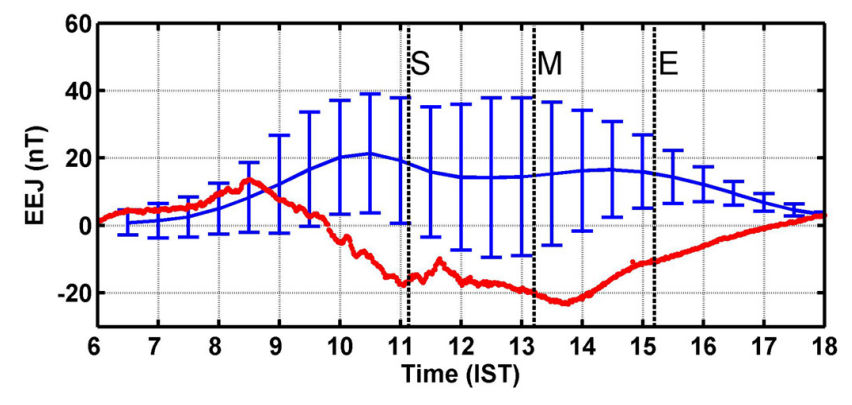

Fig. 6. Temporal variations of electrojet strength for the eclipse and control days during 06:00-18:00 IST. The blue lines with error bar represent the mean values for the control days averaged for $30 \mathrm{~min}$. Red stars correspond to the observations of eclipse day.

seen in Fig. 6, there is a strong CEEJ from around 10:00 IST to 17:00 IST on the eclipse day. This corresponds to a westward electric field which may cause a vertically downward $\boldsymbol{E} \times \boldsymbol{B}$ drift. This does not allow the plasma to be lifted to higher altitudes. It is well established that at equatorial latitudes the ionospheric electric fields drive the equatorial electrojet and $\mathrm{F}$ region plasma drifts that control the development of the equatorial ionization anomaly (EIA), and the generation of ionospheric plasma instabilities (Fejer, 2011, and references therein).

To understand and explain the observed variability in the $h^{\prime} \mathrm{F} 2$ and $h m \mathrm{~F} 2$, electrojet strength $(\Delta H=$ TirunelveliAlibag of horizontal component of the Earth's magnetic field), data on the eclipse day (every one minute) along with control days (averaged for every $30 \mathrm{~min}$ ) are shown in Fig. 6. It is important to note that, on eclipse day, counter equatorial electrojet (CEEJ) was present during 09:47 to 17:00 IST, and maximum CEEJ strength was $\sim-23 \mathrm{nT}$ at 13:45 IST, observed shortly after maximum obscuration. Different phase of equatorial electrojet (EEJ) and presence of strong counterelectrojet (CEEJ), its electrodynamics and associated phenomena during this solar eclipse have been discussed in detail by St. Maurice et al. (2011). They have shown that the electric field turned westward after the time of maximum obscurity, reaching its largest westward value one hour before the end of the local eclipse due to the fast eastward-moving local neutral wind dynamo generated by a low pressure system being triggered by the cold temperatures in the region of maximum obscuration.

Ground-based magnetometer observations of electrojet strength data during daytime have been extensively used to demonstrate the vertical $\boldsymbol{E} \times \boldsymbol{B}$ drift velocity in the equatorial F region in the Peruvian, Filipino and Indian longitude sectors under quiet and disturbed condition during 07:00 and 17:00 IST (Anderson et al., 2006, and references therein). Quiet time $\Delta H$-inferred $\boldsymbol{E} \times \boldsymbol{B}$ drift velocities are in excellent agreement with the Fejer-Scherliess, quiet time, climatological daytime $\boldsymbol{E} \times \boldsymbol{B}$ drift model (Scherliess and Fejer, 1999) in the three longitude sectors.
In general, the behavior of F2 layer is highly variable on a day-to-day basis as compared to F1 layer, because F2 layer dynamics is mostly governed by the electrodynamical processes. The vertically upward $\boldsymbol{E} \times \boldsymbol{B}$ drift pushes the plasma upward in altitude. In the meantime, the electrons tend to diffuse along the magnetic field lines to higher latitudes creating the fountain effect. So the F2 layer behavior depends not only on the production and recombination but also on the electric field. As the eclipse progressed, $h^{\prime} \mathrm{F} 2$ decreased and it followed the same pattern as that of control days. On the eclipse day, the observed variations in $h m \mathrm{~F} 2$ do not show large enhancement as expected from modeling studies (Le et al., 2009), although a slight increase in $h m F 2$ was observed for the eclipse duration. In a simulation study, Le et al. (2008a) has shown that the equatorward/poleward wind pushes $h m \mathrm{~F} 2$ upward/downward suggesting that wind direction to be poleward on this particular day. Presence of CEEJ throughout the duration of eclipse shows the presence of the westward electric field in the E region which did not allow plasma to move upward. This explains the behavior of $h^{\prime} F$ and $h m \mathrm{~F} 2$ on the eclipse day.

\section{Concluding remarks}

This paper presents initial observational results on the equatorial ionospheric observation during the longest annular solar eclipse on 15 January 2010 of this century. Ionosonde data show significant annular solar eclipse effects on E, F1 and F2 layers. Combined effect of annular eclipse and presence of CEEJ are mainly responsible for the variability in the E, F1 and $\mathrm{F} 2$ region ionospheric parameters.

Acknowledgements. We thank Observatory and Data Analysis (ODA) section of Indian Institute of Geomagnetism (IIG), Navi Mumbai for providing electrojet strength data used in this paper. One of the authors (C. K. Nayak) wishes to express his sincere thanks to Indian Institute of Geomagnetism for providing him with a Senior Research Fellowship to carry out this research work.

Editor-in-Chief M. Pinnock and Topical Editor P.-L. Blelly thank two anonymous referees for their help in evaluating this paper.

\section{References}

Adeniyi, J. O., Radicella, S. M., Adimula, I. A., Willoughby, A. A., Oladipo, O. A., and Olawepo, O.: Signature of the 29 March 2006 eclipse on the ionosphere over an equatorial station, J. Geophys. Res., 112, A06314, doi:10.1029/2006JA012197, 2007.

Afraimovich, E. L., Kosogorov, E. A., and Lesyuta, O. S.: Effects of the August 11, 1999 total solar eclipse as deduced from total electron content measurements at the GPS network, J. Atmos. Sol.-Terr. Phys., 64, 1933-1941, 2002.

Anderson, D, Anghel, A., Chau, J. L., and Yumoto, K.: Global, low-latitude, vertical $\boldsymbol{E} \times \boldsymbol{B}$ drift velocities inferred from day- 
time magnetometer observations, Space Weather, 4, S08003, doi:10.1029/2005SW000193, 2006.

Banks, P. M. and Kockarts, G.: Aeronomy (part-2), Academic Press, 1973.

Baran, L. W., Ephishov, I. I., Shagimuratov, I. I., Ivanov, V. P., and Lagovsky, A. F.: The response of the ionospheric total electron content to the solar eclipse on August 11, 1999, Adv. Space Res., 31, 989-994, 2003.

Boitman, O. N., Kalikhman, A. D., and Tashchilin, A. V.: The midlatitude ionosphere during the total solar eclipse of March 9, 1997, J. Geophys. Res., 104, 28197-28206, 1999.

Cheng, K., Huang, Y.-N., and Chen, S.-W.: Ionospheric effects of the solar eclipse of September 23, 1987, around the equatorial anomaly crest region, J. Geophys. Res., 97, 103-111, 1992.

Cohen, E. A.: The study of the effect of solar eclipses on the ionosphere based on satellite beacon observations, Radio Sci., 19, 769-777, 1984.

Datta, S., Bandyopadhyay, P., and Datta, R. N.: Ionospheric observations on the F-region during the solar eclipse of 19 April 1958, J. Atmos. Terr. Phys., 16, 182-185, 1959.

Evans, J. V.: An F region eclipse, J. Geophys. Res., 70, 131-142, 1965a.

Evans, J. V.: On the behavior of $f o \mathrm{~F} 2$ during solar eclipses, J. Geophys. Res., 70, 733-738, 1965b.

Farges, T., Jodogne, J. C., Bamford, R., Le Roux, Y., Gauthier, F., Vila, P. M., Altadill, D., Sole, J. G., and Miro, G.: Disturbances of the western European ionosphere during the total solar eclipse of 11 August 1999 measured by a wide ionosonde and radar network, J. Atmos. Sol.-Terr. Phys., 63, 915-924, 2001.

Fejer, B. G.: Low Latitude Ionospheric Electrodynamics, Space Sci. Rev., 158, 145-166, 2011.

Higgs, A. J.: Ionospheric measurements made during the total solar eclipse of 1940, October 1, Mon. Not. Roy. Astron. Soc., 102, 24-34, 1942.

Huang, C. R., Liu, C. H., Yeh, K. C., Lin, K. H., Tsai, W. H., Yeh, H. C., and Liu, J. Y.: A study of tomographically reconstructed ionospheric images during a solar eclipse, J. Geophys. Res., 104, 79-94, 1999.

Hunter, A. N., Holman, B. K., Fieldgate, D. G., and Kelleher, R.: Faraday rotation studies in Africa during the solar eclipse of June 30, 1973, Nature, 250, 205-206, 1974.

Klobuchar, J. A. and Whitney, H. E.: Ionospheric electron content measurements during a solar Eclipse, J. Geophys. Res., 70, 1254-1257, 1965.

Korenkov, Y. N., Klimenko, V. V., Bessarab, F. S., Nutsvalyan, N. S., and Stanislawska, I.: Model/Data comparison of the F2region parameters for the 11 August 1999 solar eclipse, Adv. Space Res., 31, 995-1000, 2003.
Le, H., Liu, L., Yue, X., and Wan, W.: The midlatitude F2 layer during solar eclipses: Observations and modeling, J. Geophys. Res., 113, A08309, doi:10.1029/2007JA013012, 2008a.

Le, H., Liu, L., Yue, X., and Wan, W.: The ionospheric responses to the 11 August 1999 solar eclipse: observations and modeling, Ann. Geophys., 26, 107-116, doi:10.5194/angeo-26-107-2008, 2008 b.

Le, H., Liu, L., Yue, X., Wan, W., and Ning, B.: Latitudinal dependence of the ionospheric response to solar eclipses, J. Geophys. Res., 114, A07308, doi:10.1029/2009JA014072, 2009.

Oliver, W. L. and Bowhill, S. A.: The F1 region during a solar eclipse, Radio Sci., 9, 185-195, 1974.

Pierce, J. A.: The ionospheric eclipse of October 1, 1940, Proc. IRE., 36, 137-144, 1948.

Rishbeth, H.: Solar eclipses and ionospheric theory, Space Sci. Rev., 8, 543-554, 1968

Rishbeth, H. and Garriott, O. K.: Introduction to ionospheric physics, Academic Press, 1969, International geophysics series, v. 14, 1969.

Salah, J. E., Oliver, W. L., Foster, J. C., and Holt, J. M.: Observations of the May 30, 1984, Annular Solar Eclipse at Millstone Hill, J. Geophys. Res., 91, 1651-1660, 1986.

Scherliess, L. and Fejer, B. G.: Radar and satellite global equatorial F-region vertical drift model, J. Geophys. Res., 104, 6829-6842, doi:10.1029/1999JA900025, 1999.

Skinner, N. J.: Eclipse effects in the equatorial F-region, J. Atmos. Terr. Phys., 29, 287-295, 1967. ‘

Sridharan, R., Devasia, C. V., Jyoti, N., Tiwari, Diwakar, Viswanathan, K. S., and Subbarao, K. S. V.: Effects of solar eclipse on the electrodynamical processes of the equatorial ionosphere: a case study during 11 August 1999 dusk time total solar eclipse over India, Ann. Geophys., 20, 1977-1985, doi:10.5194/angeo-20-1977-2002, 2002.

St.-Maurice, J. P., Ambili, K. M., and Choudhary, R. K.: Local electrodynamics of a solar eclipse at the magnetic equator in the early afternoon hours, Geophys. Res. Lett., 38, doi:10.1029/2010GL046085, 2011.

Tomas, A. T., Lühr, H., Förster, M., Rentz, S., and Rother, M.: Observations of the low-latitude solar eclipse on 8 April 2005 by CHAMP, J. Geophys. Res., 112, A06303, doi:10.1029/2006JA012168, 2007.

Walker, G. O., Li, T. Y. Y., Wong, Y. W., Kikuchi, T., and Huang, Y. H.: Ionospheric geomagnetic effects of the solar eclipse of 18 March 1988 in East Asia, J. Atmos. Terr. Phys., 53, 25-37, 1991. 